\title{
Sexual imprinting: The stability of mate preference in Japanese quail (Coturnix coturnix japonica)
}

\author{
JAMES E. GALLAGHER and MAUREEN ASH \\ University of San Francisco, San Francisco, California 94117
}

\begin{abstract}
This study investigated the persistence of a mate preference that resulted from early social experience. Coturnix males that achieved an imprinting criterion of selecting an imprint object (an albino conspecific hen) in 8 of 10 trials were then given one of three intervening treatments. Subjects were housed for 10 days with only normal hens or albino and normal hens, or they were isolated for the treatment period. A comparison of subsequent preference for the albino in a second series of 10 choice tests indicated that the strength of the imprinted bond is weakened with respect to the type of intervening experience. This outcome is discussed in terms of the persistence construct of the imprinting process.
\end{abstract}

One of the theoretical properties of the imprinting process is the persistence of an attachment for a class of social objects (Hess, 1973; Lorenz, 1935; Sluckin, 1973). The utility of a persistence principle in the description of imprinting would be advanced as the result of additional data describing the effects of intervening experience with nonimprinted social stimuli. Previous study of long-term social bonds indicates differences in the persistence of early preference for objects.

Immelmann (1972) described his observation of a permanent mate preference for an imprinting foster species in Zebra and Bengalese finches. Males that had been reared by foster parents of another species selected, when sexually mature, females of the foster species in preference to conspecifics. After extended confinement with conspecifics, the earlier sexual preference for the imprinted species was unchanged. This result has been since corroborated in the zebra finch (Walter, 1973). Among birds, several other investigators reported a persistence of courtship responses that were directed toward extraspecifics, usually humans, who cared for young that were isolated from conspecifics (Kruijt, 1964; Lorenz, 1935; Schein, 1963). These data illustrate persistent effects of early social experience involving speciestypical behavior directed toward a very different species. On the other hand, Cooke and McNally (1975) and Guiton (1966) reported change from the original "imprinted" preference to another object. Thus, there is a need for further data describing variables influencing the persistence of imprinted mate preference.

Requests for reprints should be addressed to James E. Gallagher, Psychology, Department, University of San Francisco, San Francisco, California 94117.
Previous study of the coturnix has demonstrated that prolonged early social experience with albino conspecific agemates establishes the adult albino hen as the preferred mate in a simulaneous choice test (Gallagher, 1976). More recently, it was observed that the process by which early social experience establishes the albino as the preferred mate is limited to an ontogenetic sensitive period (Gallagher, 1977). Sexual preference for the albino morph was not established in any case where social treatment was initiated after the 21 st day posthatch. The fact that the effect of visual social experience is limited ontogenetically in terms of establishing the albino as the preferred mate is consistent with one of the requirements for imprinting as it is typically described (Eibl-Eibesfeldt, 1975; Hess, 1973; Sluckin, 1973). Since it has been demonstrated that mate preference for albinos can be established as the result of limited early social experience, the next step is to determine if such mate preference for albinos would withstand the influence of social experience with normal females after sexual maturity.

\section{METHOD}

The subjects were 49 male Japanese quail (Coturnix coturnix japonica) hatched in a laboratory incubator. All subjects were banded and transferred to an experimental brooder on the day of hatch. Food, either Purina Startina or Layhenia, and water were provided ad lib throughout the experiment.

The experimental brooder consisted of a large room $(3.66 \times$ $1.22 \times 2.44 \mathrm{~m}$ ) that was maintained at $27 \pm 2^{\circ} \mathrm{C}$. Within the brooder room, smaller units provided chambers in which subjects could be maintained in visual isolation. The units consisted of two chambers $(24 \times 26 \times 24 \mathrm{~cm})$ that were partitioned in the center by $12-\mathrm{mm}$ wire mesh. The chamber in which the experimental chick was housed contained a 15-W lamp that was continuously lighted in order to provide an additional source of heat. The second chamber remained empty except during the experimental treatment period when it housed an adult albino hen. 
The apparatus used to test mate preference was a large rectangular box $(61 \times 122 \times 61 \mathrm{~cm})$ that consisted of $1-\mathrm{cm}$ plywood on all sides except for the front, which was a $1 \mathrm{~cm}^{2}$ wire-mesh screen. At each end of the apparatus, centered against the wall, a small wire-mesh chamber $(20 \times 20 \times 26 \mathrm{~cm})$ served to house the stimulus hens. A similarly constructed third chamber was located against the middle of the long solid wall. This chamber housed the subject prior to the start of the experimental observation period.

Exclusive exposure to an albino hen began on the 1st day posthatch and continued for a minimum of 15 days but not more than 20 days. Thus, all subjects were exposed to an albino hen during the sensitive period for establishing albino mate preference. At the end of the exposure treatment, the albino hen was removed from the brooder unit and the subject remained visually isolated until given a series of 10 simultaneous choice tests for sexual preference.

At 55 days posthatch, males were given a series of 10 choice tests using albino and normal adult hens. The behavior used as the measure of mate preference was identical to that previously used (Gallagher, 1976, 1977) and consisted of the first two phases of the standard copulatory sequence exhibited by coturnix males, the "neck-grab" and "mount." The test hens were drawn arbitrarily from different colony cages. In some cases, the same hen was used with the same male on different test trials. This procedure is appropriate, first, because of the expected low frequency of repeated use of any one test hen. There were more than 30 test hens of each morph, and test hens were changed frequently during intersubject trials. Second, Gallagher (Note 1) compared mate preference in a 10-trial test between two specific normal hens and found no preference.

In order to be included in the experiment, all subjects were required to achieve the imprinting criterion of selecting the albino hen in at least 8 of the 10 trials. Prior to the imprinting test, subjects had been assigned to one of three treatment groups which was administered after sexual preference for the albino was established. The treatment for the first group consisted of cohabitation with two normal hens for a 10-day period. The second group was housed with a normal and an albino hen during the 10-day period. The third group served as a control and remained visually isolated from other coturnix for the 10-day period. Males of the first two conditions were housed with their hens in stainless steel breeding cages $(61 \times 30 \times 41 \mathrm{~cm})$ and were otherwise visually isolated from conspecifics. This treatment differed from the earlier imprinting treatment in that the males had physical access to the hens in the breeding cage and they were sexually active. Subsequent to the intervening experimental treatment, all males were isolated for a period of $24 \mathrm{~h}$ and then tested in a second series of 10 choice tests, referred to as the "persistence" test, using the same procedure described for the imprinting test.

\section{RESULTS}

Thirty-eight of 49 males that were imprinted to an albino hen for 15-20 days posthatch achieved the imprinting criterion of selecting the albino hen in 8 of 10 trials. Subsequent data refer only to those animals that achieved the imprinting criterion.

Subjects that selected the albino hen less often in the persistence tests than in the imprinting tests were considered to have shifted toward the more recently experienced morph. The data were first analyzed to compare the frequency of shifts toward the normal hen (Table 1). A binomial test of the number of subjects that shifted mate preference was performed for each group. These tests indicate that within the
Table 1

Frequency of Mate Preference Shift

\begin{tabular}{lccc}
\hline Intervening Treatment & $\mathrm{N}$ & Shifts & $\begin{array}{c}\text { Binomial } \\
\text { Test }\end{array}$ \\
\hline Normal Hens Only & 14 & 12 & $\mathrm{p}<.01$ \\
Normal and Albino Hens & 13 & 10 & $\mathrm{p}<.05$ \\
Isolated Controls & 11 & 2 & n.s. \\
\hline
\end{tabular}

two experimental groups there is a reliable reduction in the selection of albinos in the persistence tests. No change in the strong tendency to select albinos was observed in the control group that remained isolated.

Mann-Whitney $U$ tests were performed to determine if the observed differences among independent groups were also statistically reliable. The difference in albino selection in the persistence test between controls and the experimental group that had been housed with only normal hens is statistically reliable $(\mathrm{U}=7, \mathrm{p}<.001)$. The difference in albino selection between the two experimental groups was also found to be statistically reliable $(U=34, p<.01)$. The difference in albino mate selection between the control group and the group housed with both normal and albino hens was also found to be statistically reliable $(\mathrm{U}=21.5, \mathrm{p}<.02)$.

The data were next analyzed with respect to percentage of males that remained imprinted in terms of the criterion of selecting the albino in at least 8 of the 10 choice tests. This analysis is presented in Figure 1. A chi-square test of the difference among treatment groups in the proportion of males that remained imprinted, according to the stated criterion, is statistically reliable $\left[\chi^{2}(2)=7.66, p<.05\right]$.

\section{PeRmanenCy TEST}

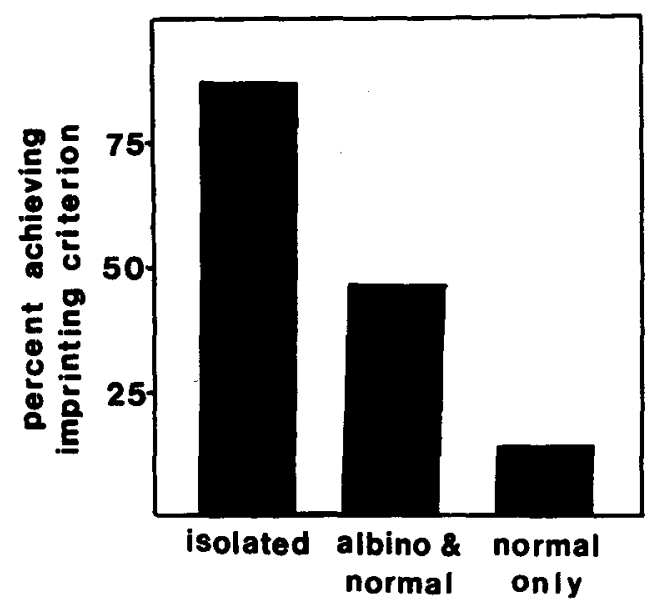

INTERVENING TREATMENT

Figure 1. The percentage of males that achieved the imprinting criterion of selecting the albino hen in 8 of the 10 trials in the persistence test. 


\section{DISCUSSION}

The establishment of mate preference for the albino morph observed in the imprinting series of choice tests resulted from treatment that is similar to the recent description of sexual imprinting in the male coturnix (Gallagher, 1977). The present findings disclosed shifts in mate preference from the albino to the normal hen that are related to the more recent social experience. The degree of shift away from the original preference for albinos is directly related to the proportion of normal hens in the intervening social treatment (Figure 1).

In view of the observed shifts the question must be asked: Do these data serve as a basis for rejecting the persistence principle of the imprinting process? It will be argued that persistence is a quality of the imprinting process affecting the original mate preference, but that such mate preference should not be thought to be immune to the effects of further (or later) experience.

Support for the above view stems from the following. First, the albino hen is not equal to the normal hen in terms of its potential for becoming a preferred mate. Males that have not been reared with extensive social experience with albinos rarely select an albino hen in a choice test. Males either reared without exposure to albinos or only exposed to albinos after the optimal sensitive period exhibit strong preferences for normal hens in the choice tests (Gallagher, 1977). In the present study, 11 of 49 males, given social experience with an albino hen during the sensitive period did not achieve the imprinting criterion. Seven of these males later selected the normal hen in at least 8 of 10 choice trials.

Second, shifting was defined as the individual's selection of the albino less frequently in the persistence test than in the imprinting test. The observed shifts toward the normal morph were not changes to a preference for the normal, e.g., a selection of the normal in six or more of the test trials. In fact, the overall preference remained in favor of the albino for the normal-albino group. In the case of the normal-only group, the data do not indicate a reliable preference subsequent to the intervening treatment, so that the normal and albino hens can be considered equivalent sex objects for this group.

Third, the control group persisted in selecting the albino hen in the persistence test (Figure 1). Hence, when free of confinement with a more potent stimulus, such as the normal hen, there is a persistent selection of the albino. The shifts in the strength of imprinted mate preference for the albino and variability in the occasional selection of the normal hen provide definite limits regarding the exclusiveness of the established social bond. More important, the shifts observed are clearly dependent upon the particular intervening experience, and are not simply the result of stimulus generalization as described for inanimate objects (Cofoid \& Honig, 1961).

It should be noted that while the intervening treatment employed in this study approximated that of the Immelmann (1972) and Walter (1973) studies, our data disclosed an attenuation of the original mate preference. This fact may be the result of a number of factors, such as, species differences, difference in the taxonomic proximity of the albino to a conspecific, difference in the strength of the pair bond, or some composite of these factors. Recent comparison of the persistence for normal or albino morphs suggests that the attenuation of mate preference may be limited to the albino morph (Gallagher, Note 2).

In conclusion, it can be stated that the property of persistence is not an all-or-none effect, but is, rather, dependent upon conditions such as intervening experience and the nature of the imprinting object. Nevertheless, the social bond produced by imprinting has some persistence.

\section{REFERENCE NOTES}

1. Gallagher. J. E. Incest in Japanese quail (Coturnix coturnix japonica). Paper presented at the meeting of the Western Psychological Association, Los Angeles, 1976.

2. Gallagher, J. E. Differences in persistence of imprinted preferences due to stimulus property. Paper presented at the meeting of the American Psychological Association. San Francisco. 1977.

\section{REFERENCES}

Coford. D. A., \& Honig. W. K. Stimulus generalization of imprinting. Science, 1961, 134, 1692-1693.

Cooke, F., \& MCNALLY, C. Mate selection and colour preferences in lessor snow geese. Behaviour, 1975, 53, 151-170.

EIBL-EIBESFELDT, I. Ethology: The biology of behavior (2nd ed.). New York: Holt, Rinehart \& Winston, 1975.

GallaGher, J. E. Sexual imprinting: Effects of various regimens of social experience in Japanese quail (Coturnix coturnix japonica). Behaviour. 1976, 57, 91-115.

Gallagher. J. E. Sexual imprinting: A sensitive period in Japanese quail (Coturnix coturnix japonica). Joumal of Comparative and Physiological Psychology, 1977, 91, 72-78.

Guiton. P. Early experience and sexual object-choice in the Brown Leghorn. Animal Behaviour, 1966, 14, 534-538.

HEss, E. H. Imprinting: Early experience and the developmental psychobiology of attachment. New York: Van Nostrand Reinhold, 1973.

IMmELMANN, K. Sexual and other long term aspects of imprinting in birds and other species. In D. S. Lehrman, R. A. Hinde, \& E. Shaw (Eds.), Advances in the study of behavior (Vol. 4). New York: Academic Press, 1972.

KRUiJT, J. P. Ontogeny of social behaviour in Burmese red junglefowl (Gallus gallus spadieceus Bonnaterre). Behaviour Supplement, 1964, 12.

LoREnz, K. Der Kumpan in der Umwelt des Vogels. Journal of Ornithology, 1935, 83, 137-413.

Schein. M. W. On the irreversibility of imprinting. Zeitschrift für Tierpsychologie, 1963, 20. 462-467.

SLuckin. W. Imprinting and early learning (2nd ed.). Chicago: Aldine, 1973.

WALTER, M. J. Effects of parental colouration on the mate preference of offspring in the zebra finch (Taeniopygia gutata castanotis gould). Behaviour. 1973, 46. 154-173. 